\title{
An Evaluation and Correlation of Leptin in Gingival Crevicular Fluid and Serum in Health, Gingivitis and Periodontitis
}

\author{
Vinay Hanumanthrao Vadvadgi, Rajiv Saini, Neeta Padmawar
}

\begin{abstract}
Background and objective: Plasma leptin is associated in patients with inflammatory diseases. A high concentration of leptin is associated with healthy gingival tissue. The purpose of this study was to assess the concentration of human leptin in gingival crevicular fluid (GCF) and serum within healthy and diseased gingiva, further to explore the possibility of using the levels of leptin in GCF and serum as a biochemical marker of periodontal disease progression.
\end{abstract}

Materials and methods: Ninety subjects were selected with age (30-39 years) and sex ( 15 males and 15 females) matched, to eliminate age and sex as confounders. The subjects were divided into three groups consisting of 30 subjects in each group based on the clinical and radiological parameters; healthy (group I), gingivitis (group II), periodontitis (group III), from whom the GCF samples were collected with Periopaper GCF collection strips (P roflow, Amityville, NY, USA) for 30 seconds and blood samples with 20 -gauge needle syringe respectively. Leptin concentration was determined from individual GCF and serum samples by enzyme-linked immunosorbent assay (ELISA).

Results: The highest mean leptin concentration in GCF was observed in group I $(2,664.30 \mathrm{pg} / \mathrm{ml} \pm 324.73)$ and least mean leptin concentration was obtained in group III $(1,309.43 \mathrm{pg} / \mathrm{ml} \pm$ $202.45)$. The mean concentration of group II $(1,639.43 \mathrm{pg} / \mathrm{ml} \pm$ 344.46) was intermediate between the highest and lowest values. In contrast, the highest mean leptin concentration in serum was obtained for group III $(12,086.57 \mathrm{pg} / \mathrm{ml} \pm 1,698.23)$ and least mean leptin concentration was obtained for group I $(8,715.09 \mathrm{pg} / \mathrm{ml} \pm 1,649.19)$. The mean concentration of the group II $(10,694.01 \mathrm{pg} / \mathrm{ml} \pm 1,777.72)$ were intermediate between the highest and lowest values.

Conclusion: The results indicated a statistically significant decrease in the GCF leptin concentration and increase in serum leptin concentration as the periodontal disease progressed.

Keywords: Leptin, Periodontitis, Serum.

How to cite this article: Vadvadgi $\mathrm{VH}$, Saini R, Padmawar $\mathrm{N}$. An Evaluation and Correlation of Leptin in Gingival C revicular Fluid and Serum in Health, Gingivitis and Periodontitis. Int J Experiment Dent Sci 2012;1(2):93-97.

Source of support: Nil

Conflict of interest: None declared

\section{INTRODUCTION}

Leptin (ob), a product of the ob gene, is a $16-k D a$ nonglycosylated peptide hormone. It is synthesized mainly in adipocytes and in minor quantities by placenta, $T$ cells, osteoblasts and gastric epithelium, which regulate weight control and modulate other physiological functions, reproductive and hematopoietic systems and bone remodeling. Leptin also enhances the immune system, as it stimulates macrophages. Leptin is associated with healthy gingival tissue and the concentration of leptin decreases as periodontal disease progresses. Periodontal diseases are multifactorial in etiology. Although microorganisms are implicated as the etiologic agent that induces inflammation, however, the chemical mediators of inflammation play a pivotal role in the loss of connective tissue, as well as supporting alveolar bone. Cytokines such as interleukin$1 \beta$, tumor necrosis factor- $\alpha$, prostaglandin E2, and more recently adipokines, leptin, have been shown to orchestrate the host response to infectious and inflammatory stimuli. ${ }^{1}$ Hence, the present study was designed to assess the concentration of human leptin in gingival crevicular fluid (GCF) and serum and to find out their link, if any, in periodontal health and disease; further, to get deeper insight into its possible role in commencement and development of periodontal disease.

\section{MATERIALS AND METHODS}

The present study was conducted in the Department of Periodontology, Rural Dental College, L oni, M aharashtra, in coordination with Department of Biochemistry, Rural M edical College of Pravara Institute of M edical Sciences, L oni, A hmednagar, M aharashtra, India. The ethical clearance of the study was obtained from the ethical and research committee of Rural D ental College and H ospital, Loni.

\section{Study Population}

The study population consisted of 90 subjects who were randomly selected, attending the outpatient section, Department of Periodontics, Rural Dental College and H ospital, L oni. W ritten informed consent was obtained from those who agreed to participate voluntarily. The subjects enrolled in the study were aged between 30 and 39 years, subjects who had not received any periodontal treatment in last 6 months, dentition with at least 20 functioning teeth, patients who fall in normal body mass index (BMI), chart of W orld Health Organization (W H O), subjects should not be taking any medications affecting periodontal health and free from medical diseases. Exclusion criterias were: (i) 
Patient suffering from aggressive periodontitis, (ii) patients with bleeding disorders, (iii) patients with gross oral pathology, (iv) treatment in the previous 6 months with antiinflammatory drugs or antibiotics, (v) patients having anomalies of the immune system, (vi) pregnant and lactating women, (vii) conditions elicited by a medical history likely to influence the inflammatory response, (viii) patients with liver, biliary, prostate and pancreatic cancer, (ix) al coholism and smoking.

\section{Subject Grouping}

B ased on the modified gingival index, Ramfjord periodontal disease index and radiograph evidence of boneloss, patients were categorized into three groups. Group I (healthy) consisted of 30 patients who had clinically healthy gingiva with no loss of clinical attachment. Group II (chronic gingivitis with no loss of attachment) comprised 30 patients who showed clinical signs of gingival inflammation without any attachment loss. Group III (chronic periodontitis) comprised 30 patients who showed clinical signs of gingival inflammation with loss of attachment.

\section{Procedure of Serum Collection}

Two milliliters of blood was collected from the antecubital fossa by venipuncture using 20-gauge needle with $2 \mathrm{ml}$ syringes and immediately transferred to laboratory. Blood sample was allowed to clot at room temperature and after 1 hour, serum was extracted from blood by centrifuging at $3,000 \mathrm{~g}$ for 5 minutes. The extracted serum was immediately transferred to plastic vial and stored at $-70^{\circ} \mathrm{C}$ till the time of assay. Samples were then assayed for leptin levels by using enzyme-linked immunosorbent assay (ELISA) kit obtained from Biosource Europe SA (catalog \#K A P 2281, batch 092601). Samples were analyzed at Department of Biochemistry, Rural M edical College, Loni, using ELISA method.

\section{Procedure for GCF Collection}

Subjects selected for sampling were made to sit comfortably in an upright position on the dental chair with proper illumination. The test site selected based on the periodontal status for sampling was air dried, isolated with cotton roll and supragingival plaque was removed without touching marginal gingiva. Sample of GCF were obtained before probing the site by placing Periopaper GCF collection strips (Proflow, A mityville, NY, USA) for 30 seconds. The test site was selected based on the periodontal status and GCF was collected. After collection of GCF, the sample was assigned to a particular group based on the gingival inflammation, attachment loss and radiographic bone loss.
The strip was placed intracrevicularly until the minimum resistance was obtained at the mesiofacial, distofacial or midfacial surface of the tooth. Paper strips contaminated with blood or pus and saliva were excluded from the study. Samples of the GCF were taken at the initial visit. To avoid stimulation of GCF flow, all participants were instructed not to eat anything or brush their teeth for at least $\geq 1$ hour prior to GCF sampling. For standardization, all GCF samples were collected between 9.00 and $10.00 \mathrm{am}$. The GCF collected was immediately transferred to plastic vial and stored at $-70^{\circ} \mathrm{C}$ till the time of assay.

\section{Estimation of Leptin}

The Biosource Europe SA human leptin kit is a solid phase sandwich ELISA. A monoclonal antibody specific for human leptin has been coated onto the wells of the microtiter strips provided. Samples, including standards of known leptin content, control specimens and unknowns, are pipetted into these wells followed by the addition of a second biotinylated monoclonal antibody. During the firstincubation, the leptin antigen binds to the immobilized (capture) antibody on one site and to the solution phase biotinylated antibody on a second site. A fter removal of excess second antibody, streptavidin-peroxidase (enzyme) is added. This binds to the biotinylated antibody to complete the four-member sandwich. A fter a second incubation and washing to remove the entire unbound enzyme, a substrate solution is added, which is acted upon by the bound enzyme to produce color. The intensity of this colored product is directly proportional to the concentration of leptin present in the original specimen.

\section{STATISTICAL ANALYSIS}

The statistical analysis were done by using Student t-test, unpaired t-test and $\mathrm{K}$ arl Pearson's coefficient of correlation (r).

\section{RESULTS}

Distribution of mean and standard deviation values of all parameters (gingival index, periodontal disease index, clinical attachment loss, gingival crevicular fluid and serum) in all groups under study were illustrated in Graph 1.

All the samples in each group tested positive for leptin assay. The highest mean leptin concentration in GCF was obtained for group I $(2,664.30 \mathrm{pg} / \mathrm{ml})$ and least mean leptin concentration was obtained for group III $(1,309.43 \mathrm{pg} / \mathrm{ml})$. The mean concentration of the group II $(1,639.43 \mathrm{pg} / \mathrm{ml})$ were intermediate between the highest and lowest values. In contrast, the highest mean leptin concentration in serum was obtained for group III $(12,086.57 \mathrm{pg} / \mathrm{ml})$ and least mean leptin concentration was obtained for group I $(8,715.09 \mathrm{pg} / \mathrm{ml})$. 
An Evaluation and Correlation of Leptin in Gingival C revicular Fluid and Serum in Health, Gingivitis and Periodontitis

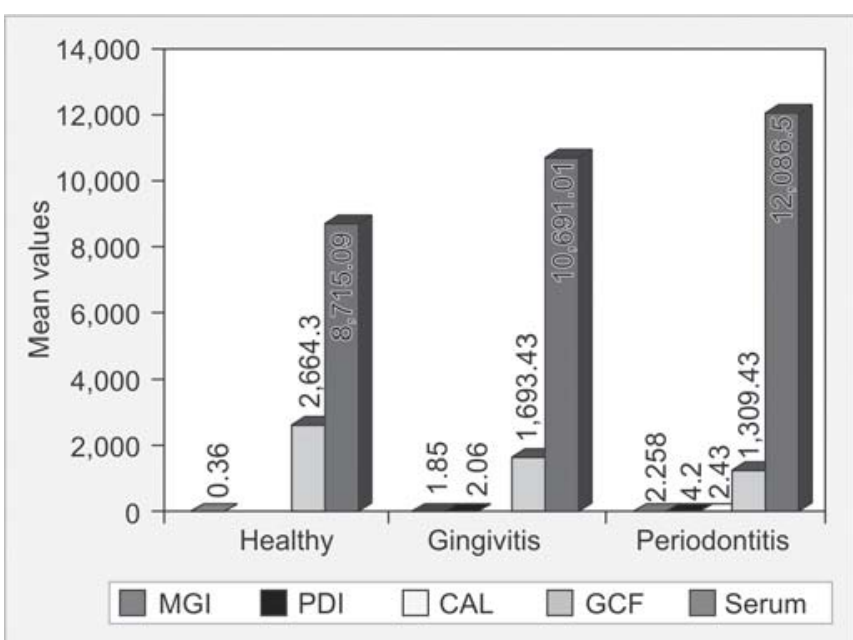

Graph 1: Distribution of mean and SD values of all parameters in all groups under study

The mean concentration of the group II $(10,694.01 \mathrm{pg} / \mathrm{ml})$ were intermediate between the highest and lowest values. These results are shown in Table 1 and Graph 2. Students unpaired t-test was done to observe for any correlation between the GCF and serum leptin concentration. The resul ts of the test show ed a significant negative correlation between the GCF and serum leptin concentration. Further, when leptin levels in GCF and serum were tested for correlation with the disease severity measures, i.e. modified gingival index (M GI; in group I), M GI, periodontal disease

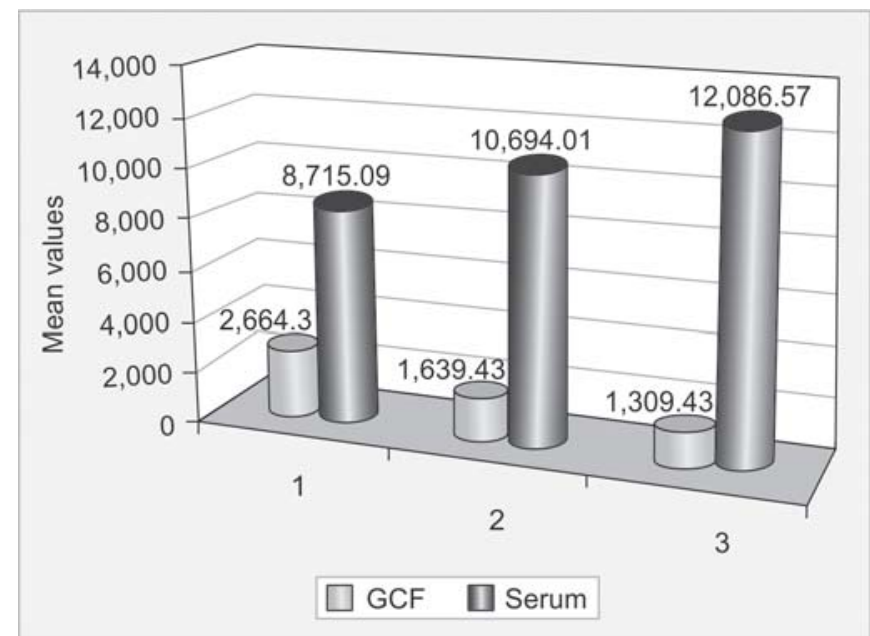

Graph 2: Mean concentration of leptin in GCF and serum compared among study groups

index (PDI; in groups II and III) and M GI, PDI and clinical attachment level (CA L; in group III), a negative correlation was found for GCF leptin concentration and a positive correlation for the serum leptin concentration. This suggests that leptin levels in both GCF and serum are inversely proportion to each other. The results are tabulated in Tables 2 to 4 . When Karl Pearson correlation coefficient between $\mathrm{CAL}$ and GCF (pg/ml) test was done to compare the mean leptin concentration in GCF and serum at different CAL levels, there was a statistically significant reduction of GCF

$\begin{array}{lccc} & \text { Table 1: Distribution of mean and SD values of all parameters in all groups under study } \\ \text { Parameters/groups } & \begin{array}{c}\text { Group I }(n=30) \\ \text { Mean } \pm \text { SD }\end{array} & \begin{array}{c}\text { Group II }(n=30) \\ \text { Mean } \pm \text { SD }\end{array} & \begin{array}{c}\text { Group III }(n=30) \\ \text { Mean } \pm S D\end{array} \\ \text { MGI } & 0.36 \pm 0.14 & 1.85 \pm 0.41 & 2.258 \pm 0.28 \\ \text { PDI } & - & 2.06 \pm 0.49 & 4.20 \pm 0.36 \\ \text { CAL } & - & - & 2.43 \pm 1.02 \\ \text { GCF } & 2,664.30 \pm 324.73 & 1,639.43 \pm 344.46 & 1,309.43 \pm 202.45 \\ \text { Serum } & 8,715.09 \pm 1,649.19 & 10,694.01 \pm 1,777.72 & 12,086.57 \pm 1,698.23\end{array}$

From the above table, it is seen that the mean values of the MGI in healthy group is 0.36 which is less than in gingivitis group (i.e. 1.85 ) and maximum (i.e. 2.258) in periodontitis group

\begin{tabular}{lccccc} 
Parameters/groups & \multicolumn{4}{c}{ Table 2: Comparison of mean values of MGI, GCF and serum in groups I and II } \\
& $\begin{array}{c}\text { Healthy }(n=30) \\
\text { Mean } \pm \text { SD }\end{array}$ & $\begin{array}{c}\text { Gingivitis }(n=30) \\
\text { Mean } \pm \text { SD }\end{array}$ & t-value & p-value & Significance \\
MGI & $0.36 \pm 0.14$ & $1.85 \pm 0.41$ & 18.87 & $<0.01$ & Highly significant \\
PDI & - & $2.06 \pm 0.49$ & 26.06 & $<0.01$ & Highly significant \\
GCF & $2,664.30 \pm 324.73$ & $1,639.43 \pm 344.46$ & 11.86 & $<0.01$ & Highly significant \\
Serum & $8,715.09 \pm 1,649.19$ & $10,694.01 \pm 1,777.72$ & 4.47 & $<0.01$ & Highly significant
\end{tabular}

\begin{tabular}{lccccc} 
Table 3: Comparison of mean values of MGI in GCF and serum in groups I and III & \\
Parameters/groups & $\begin{array}{c}\text { Healthy }(n=30) \\
\text { Mean } \pm \text { SD }\end{array}$ & $\begin{array}{c}\text { Periodontitis }(n=30) \\
\text { Mean } \pm \text { SD }\end{array}$ & t-value & p-value & Significance \\
MGI & $0.36 \pm 0.14$ & $2.258 \pm 0.28$ & 33.25 & $<0.01$ & Highly significant \\
PDI & - & $4.20 \pm 0.36$ & 63.90 & $<0.01$ & Highly significant \\
CAL & - & $2.43 \pm 1.02$ & 13.05 & $<0.01$ & Highly significant \\
GCF & $2,664.30 \pm 324.73$ & $1,309.43 \pm 202.45$ & 19.39 & $<0.01$ & Highly significant \\
Serum & $8,715.09 \pm 1,649.19$ & $12,086.57 \pm 1,698.23$ & 7.81 & $<0.01$ & Highly significant \\
\hline
\end{tabular}


Vinay Hanumanthrao Vadvadgi et al

Table 4: Comparison of mean values of MGI, PDI, GCF and serum in groups II and III

$\begin{array}{lccccc}\text { Parameters/groups } & \begin{array}{c}\text { Group II }(n=30) \\ \text { Mean } \pm \text { SD }\end{array} & \begin{array}{c}\text { Group III }(n=30) \\ \text { Mean } \pm \text { SD }\end{array} & \text { t-value } & \text { p-value } & \text { Significance } \\ \text { MGI } & 1.85 \pm 0.41 & 2.258 \pm 0.28 & 4.49 & <0.01 & \text { Highly significant } \\ \text { PDI } & 2.06 \pm 0.49 & 4.20 \pm 0.36 & 19.45 & <0.01 & \text { Highly significant } \\ \text { CAL } & - & 2.43 \pm 1.02 & 13.05 & <0.01 & \text { Highly significant } \\ \text { GCF } & 1,639.43 \pm 344.46 & 1,309.43 \pm 202.45 & 4.52 & <0.01 & \text { Highly significant } \\ \text { Serum } & 10,694.01 \pm 1,777.72 & 12,086.57 \pm 1,698.23 & 3.10 & <0.01 & \text { Highly significant }\end{array}$

Table 5: Karl Pearson's correlation coefficient $(r)$ between parameters CAL and GCF (pg/ml) and correlation between CAL and serum $(\mathrm{pg} / \mathrm{ml})$

\begin{tabular}{lcl}
$\begin{array}{l}\text { Correlation coefficient } \\
\text { between }\end{array}$ & $\begin{array}{c}\text { Karl Pearson's } \\
\text { correlation } \\
\text { coefficient }(r)\end{array}$ & Result \\
\hline CAL and GCF & -0.96 & Negative correlation \\
CAL and serum & 0.13 & Positive correlation
\end{tabular}

leptin levels and increase in serum leptin levels as CA L progressed. The results are tabulated in Table 5 . In summary, further, these results indicate that GCF leptin concentration decreases from periodontal health to disease with a concomitant raise in serum leptin levels.

\section{DISCUSSION}

Leptin is a hormone that is secreted into the blood in varying quantities by adipocytes and regulates weight in a central manner, via its cognate receptor in the hypothal amus thereby suppressing hunger; moreover, it is also known to stimulate lipid metabolism. ${ }^{2,3}$ Recently, leptin concentrations in healthy and diseased gingiva were estimated and found to have a negative correlation between the leptin and interleukin- 6 concentrations as the periodontal disease progressed. This suggests that the leptin is present within the heal thy gingiva and its concentration declines coincident to the severity of gingival inflammation and periodontal pocket formation. ${ }^{4}$ H owever, in their study no attempts were made to estimate serum leptin concentration so as to know its correlation with gingival leptin concentration. Hence, the present study was undertaken, which is to assess the concentration of human leptin levels in GCF and serum from healthy periodontium, gingivitis and chronic periodontitis patients.

In this study, to control variables like age and sex influencing the levels of leptin, we selected subjects with equal number of males and females, who fell under the age range of 30 to 39 years, in all the three groups. Further, we estimated the concentration of leptin in GCF to avoid gingival biopsies as done in the earlier study ${ }^{4}$ for making the sample collection atraumatic. M oreover, to avoid leptin derived from obese subjects biasing the estimation of leptin concentration, they were excluded from the study by selecting subjects who fell in normal BM I chart for A sian population given by WHO in $2002\left(18.5-22.9 \mathrm{~kg} / \mathrm{m}^{2}\right) .^{5}$

The results of the current study show ed that a mean GCF leptin concentration in healthy group was $2,664.30 \mathrm{pg} / \mathrm{ml}$, gingivitis group was $1,639.43 \mathrm{pg} / \mathrm{ml}$ and in periodontitis group was $1,309.43 \mathrm{pg} / \mathrm{ml}$. This shows that there is a strong negative correlation between the GCF leptin concentration and periodontal disease progression. The results obtained from our study were in accordance with the study done by Johnson and Serio, ${ }^{4}$ who also showed that leptin concentration is correlated negatively with the probing pocket depth. Further, mean serum leptin concentration in healthy group was $8,715.09 \mathrm{pg} / \mathrm{ml}$, in gingivitis group was $10,694.01 \mathrm{pg} / \mathrm{ml}$ and in periodontitis group was $12,086.57$ $\mathrm{pg} / \mathrm{ml}$. Hence, serum leptin concentrations were positively correlated with the periodontal disease progression.

It has been suggested that rise in serum leptin concentration acts as a risk factor for cardiovascular diseases as it promotes atherosclerosis by enhancing platelet aggregation, ${ }^{6}$ neovascularization of atherogenic plaque, ${ }^{7}$ induction of oxidative stress in arterial wall ${ }^{8}$ and also acceleration of hepatic degradation and clearance of high density lipoprotein (HDL) apoproteins. ${ }^{9}$ Further, it induces calcification of arterial walls, thereby losing elasticity (distensibility), making them stiffer. ${ }^{10}$ This reduces blood flow and increases heart exertion thereby increasing workload on the heart. The rise in serum leptin levels above $10,000 \mathrm{pg} / \mathrm{ml}$ is considered as a risk factor for cardiovascular disease. ${ }^{11}$ In this study, as the periodontal disease progressed there was raise in serum leptin concentration on an average up to $12,086.57 \mathrm{pg} / \mathrm{ml}$. Based on this, it could be hypothesized that raise in serum leptin concentration due to periodontal disease could act as one of the risk factors for cardiovascular disease. How ever, longitudinal studies are required to confirm this possibility.

\section{CONCLUSION}

Within the limitations of this study, it can be postulated that greater the extent of periodontal destruction, lesser is the GCF leptin concentration and greater the serum leptin concentration. This observation extends our knowledge of the protective role of leptin in periodontal health. Further, 
An Evaluation and Correlation of Leptin in Gingival Crevicular Fluid and Serum in Health, Gingivitis and Periodontitis

increased serum leptin concentration is a known risk factor for cardiovascular disease. This increase due to periodontal disease progression, as seen in our study, indicates that latter may raise the risk of developing cardiovascular disease. There is a need for further studies with a larger sample size to investigate the spatial and temporal relationship of changes in GCF and serum leptin levels with the development of periodontal inflammation and ultimately the progression from gingivitis to periodontitis.

\section{REFERENCES}

1. Garlet GP, M artins W J r, Fonseca BA L, Ferreira BR, Silva J S. $M$ atrix metalloproteinases, their physiological inhibitors and osteoclast factors are differentially regulated by the cytokine profile in human periodontal disease. J Clin Periodontol 2004; 31:671-79.

2. Zhang $F$, Basinski $M B, B$ eals J M, B riggs $S L$, Churgay $L M$, Clawson DK, et al. Crystal structure of the obese protein leptinE100. Nature 1997;387:206-09.

3. A gnello D, M eazza C, Rowan CG, V illa P, Ghezzi P, Senaldi $G$, et al. L eptin causes body weight loss in the absence of in vivo activities typical of cytokines of the IL - 6 family. A m J Physiol 1998;275:R913-19.

4. Johnson RB, Serio FG. Leptin within healthy and diseased human gingiva. J Periodontol 2001;72:1254-57.

5. WHO Expert Consultation. Appropriate body-mass index for A sian populations and its implications for policy and intervention strategies. Lancet 2004;363:157-63.

6. Nakata M, Toshihiko Y, Soejima N, M aruyama L. Leptin promotes aggregation of human platelets via the long form of its receptor. Diabetes 1999;48:426-29.

7. Kang SM, K won HM, H ong BK, K im D, K im IJ, Choi EY, et al. Expression of leptin receptor (Ob-R) in human atherosclerotic lesions: Potential role in intimal neovascularization. $Y$ onsei $\mathrm{M}$ ed J 2000;41:68-75.

8. Beltowski J, Wojcicka G, Jamroz A. L eptin decreases plasma paraoxonase 1 (PON 1) activity and induces oxidative stress: The possible novel mechanism for proatherogenic effect of chronic hyperleptinemia. A therosclerosis 2003;170:21-29.

9. Silver DL, J iang XC, Tall A R. I ncreased high density lipoprotein (HDL), defective hepatic catabolism of ApoA-I and A poA-II, and decreased ApoA-I mRNA in ob/ob mice. J Biol Chem $1999 ; 274: 4140-46$.

10. Parhami F, Tintut $Y$, B allard A, Fogelman A M, Demer LL. Leptin enhances the calcification of vascular cells artery wall as a target of leptin. Circ Res 2001;88:954-60.

11. Y amagishi SI, Edelstein D, Du XL, K aneda Y, Guzma M, Brownlee $M$, et al. Leptin induces mitochondrial superoxide production and monocyte chemoattractant protein- 1 expression in aortic endothelial cells by increasing fatty acid oxidation via protein kinase A. J Biol Chem 2001;276:25096-100.

\section{ABOUT THE AUTHORS}

\section{Vinay Hanumanthrao Vadvadgi (Corresponding Author)}

Senior L ecturer, D epartment of Periodontology, Pravara Institute of M edical Sciences, A hmednagar, $M$ aharashtra, India, e-mail: periodontist29@gmail.com

\section{Rajiv Saini}

A ssistant Professor, D epartment of Periodontology, Pravara Institute of M edical Sciences, A hmednagar, M aharashtra, India

\section{Neeta Padmawar}

L ecturer, Department of Oral Pathology, Pravara Institute of M edical Sciences, A hmednagar, M aharashtra, India 